\title{
PENGARUH LATIHAN KELENTUKAN TERHADAP HASIL TENDANGAN DOLLYO CHAGI PADA ATLET TAEKWONDO
}

\author{
Aldho Falta cifero ${ }^{1}$, Ronni yenes ${ }^{2}$,Vega Soniawan ${ }^{3}$, Yogi Setiawan ${ }^{4}$ \\ ${ }^{1}$ Fakultas Ilmu Keolahragaan, Universitas Negeri Padang, Indonesia \\ ${ }^{2}$ Universitas Negeri Jakarta, Indonesia.
}

\section{Informasi Artikel}

Diterima2020-11-23

Direvisi2021-02-24

Dipublikasikan 2021-03-06

\section{Keyword:}

Flexibility Training

Dollyo Chagi Kick

\begin{abstract}
The problem in this study is the alleged lack of maximum dollyo chagi kick ability in athletes. This research aims to find out how much flexibility exercise affects the results of Dollyo Chagi Taekwondo Athlete Dojang Lebong kicks.This type of research is pseudo-experimental research, conducted against the kick dollyo chagiatlet taekwondo Dojang Lebong. The population in this study was taekwondo athlete Dojang Lebong who numbered 55 people. The research sample was taekwondo athlete Dojang Lebong as many as 8 people, with proposivesampling technique. The test instruments used in this study were dollyo chagi kick tests, while statistical data analysis techniques used normality tests, data homogeneity tests and t-tests with a significant level of 0.05.The results of the study,there is an effect of flexibility exercise on the kick dollyo chagi taekwondo athlete dojang lebong obtained that $\mathrm{t}$ hitung $=3.64>\mathrm{t}$ tabel $=1.89$.then the average pre test value $=13.88$ and the average post test value $t=$ 16.25 , because the average post test value is greater than the average pre test value then there is an increase in dollyo chagi kick capability $=2.38$
\end{abstract}

(C) 2020 The Authors. Published by Universitas Negeri Padang. This is an open access article under the CC BY-NC-SA license (https://creativecommons.org/licenses/by-nc-sa/4.0/

\section{Penulis Korespondensi:}

Aldho Falta Cifero

Universitas Negeri Padang

Email:, aldolebong27@gmail.com,

\section{PENDAHULUAN}

Taekwondo merupakan olahraga beladiri yang berasal dari Korea yang tumbuh di Indonesia. Tingginya antusias masyarakat Indonesia untuk mempelajari olahraga taekwondo tentu didorong oleh berbagai tujuan dan alasan. Adapun tujuan tersebut antara lain untuk kebugaran, sebagai bela diri, dan yang paling dominan adalah untuk prestasi. Jika keikutsertaan individu mengikuti olahraga taekwondo untuk mengembangkan potensi diri, maka olahraga taekwondo tersebut sudah masuk kedalam kelompok olahraga prestasi yang dikembangkan dan dikompetisikan secara bertahap mulai dari tingkat daerah, nasional, dan bahkan internasional.Berdasarkan Undangundang RI No. 3 tahun 2005 tentang Sistem Keolahragaan Nasional bagian keempat pembinaan dan pengembangan olahraga prestasi Pasal 27 ayat (1) dan (4) menjelaskan: Ayat (1): "Pembinaan dan pengembangan olahraga prestasi dilaksanakan dan diarahkan untuk mencapai prestasi 
olahraga pada tingkat daerah, nasional dan internasional". Ayat (4): "Pembinaan dan pengembangan olahraga prestasi dilaksanakan dengan memberdayakan perkumpulan olahraga yang bersifat nasional dan daerah dengan menyelenggarakan kompetisi secara berjenjang dan berkelanjutan.

Soniawan dan Irawan menyatakan (2018:42) Pemeliharaan dan Pembinaan olahraga prestasi dilaksanakan dengan memperkuat kelompol dalam olahraga, memajukan sentra pengembangan olahraga seluruh Indonesia, dan menyelenggarakan kompetisi secara berjenjang dan berkelanjutan.Untuk mencapai prestasi taekwondo yang optimal harus dilakukan dengan pembinaan dari semua pihak yang dimulai secara berjenjang dan berkelanjutan, baik melalui jalur pendidikan, jalur keluarga, dan jalur masyarakat yang berbasis pada proses pengembangan olahraga untuk semua orang yang berlangsung secara berkelanjutan (Setiawan, 2018:16).

Pembinaan kondisi fisik sangat mempengaruhi prestasi seorang atlet. Kondisi fisik (physical condition) atau kemampuan fisik merupakan salah satu komponen dasar untuk meraih prestasi olahraga (Ihsan, 2018:2). Kondisi fisik adalah bagian terpenting dalam olahraga yang harus dilengkapi oleh atlit taekwondo di dalam memperoleh upaya prestasi olahraga yang optimal (Ridwan, 2020:66).Tanpa memiliki kondisi fisik yang baik atlet akan sangat mustahil untuk mencapai prestasi maksimalnya (Inggar, 2020:17).Secara umum setiap cabang olahraga membutuhkan kondisi fisik yang baik, artinya setiap cabang olahraga membutuhkan kondisi fisik untuk mencapai prestasi yang maksimal (Saputra, 2020:6).Erianti dalam Dedi berpendapat (2020:12) komponen-komponen kondisi fisik yang mempengaruhi prestasi yaitu:" daya tahan (endurance), kelentukan (flexibility), kecepatan (speed) ,kekuatan (strength), daya ledak (exsplosive power),reaksi (reaction),kelincahan (agility),".

Taekwondo merupakan olahraga beladiri yang berasal dari Korea (Firdaus, 2018:2).Setiawan (2018:16) menyatakan taekwondo adalah olahraga beladiri yang memakai kemampuan teknik kaki dan tangan kosong, dimana inti dari konsep taekwondo adalah gabungan dari kekuatan dan kemampuan . Oleh karena itu, baik teknik dan kemampuan fisik harus bagus agar berhasil dalam pelatihan atau dalam kompetisi, terutama dalam menggunakan teknik serangan tendangan (Setiawan,2017;524). Maka jika diartikan dengan mudah taekwondo berarti seni atau cara keahian diri atau seni bela diri yang menggunakan teknik kaki dan tangan kosong.Olahraga taekwondo sangat memerlukan Kekuatan, kecepatan, stamina, keseimbangan, kelenturan, dan koordinasi, merupakan kompenen yang penting bagi seorang atlet taekwondo untuk dapat melakukan kombinasi tendangan dinamis yang digunakan dalam taekwondo (Lystad,2009:15). Gabungan tendangan inisering kali menggunakan tendangan lanjutan seperti, melompat, berputar, dan meluncur. Di dalam pertandingan taekwondo mental dan fisik sangat menentukan kondisi atlet saat di arena pertandingan .

Berdasarkan observasi dan pengamatan yang dilakukan oleh penulis terhadap atlet taekwondo Lebong pada saat latihan di dojang kemudian survey ketempat uji coba dengan club taekwondo yang lain dan dalam ajang pertandingan yang mereka ikuti, teknik tendangan dollyo chagi lah yang paling sering digunakan karena tendangan dollyo chagi dianggap tendangan yang cepat, simpel dan efektif untuk melakukan serangan, kemudian telah diamati teknik tendangan dollyo chagi yang digunakan masih lemah, kaku, kurang efisien dan kurang lentur sehingga susah untuk menendang tinggi terutama kearah sasaran kepala.Sehingga mengakibatkan kurang maksimalnya kemampuan tendangan dollyo chagi pada atlet.

Berdasarkan uraian diatas, maka peneliti tertarik untuk mengangkat faktor latihan kelentukan yang mempengaruhi kemampuan tendangan dollyo chagi, bagi atlet-atlet taekwondo Lebong, yaitu melalui latihan kelentukan. Ketertarikan ini didasari dari suatu pandangan bahwa meningkatkan kemampuan tendangan dollyo chagi tidak hanya memalui latihan konvensional saja, tetapi juga dapat dilakukan dengan meningkatkan unsur-unsur yang menunjang dalam gerakan tersebut dengan bentuk latihan yang berbeda. Oleh karena itu peneliti memutuskan untuk memberi judul dalam penelitian ini yaitu:"Pengaruh Latihan Kelentukan Terhadap Hasil Tendangan Dollyo chagi Pada Atlet Taekwondo Lebong Provinsi Bengkulu".

\section{METODE}

Jenis Penelitian ini merupakan penelitian eksperimen semu (quasi experimental) yang dilakukan terhadap atlet taekwondo Dojang Lebong dimana metode peneltian yang digunakan 
untuk mengetahui ada tidaknya akibat dari sesuatu yang diberikan pada subjek selidik. Penelitian ini bermaksud untuk mencari pengaruh latihan kelentukan terhadap hasil tedangan dollyo chagi pada atlet Taekwondo Lebong.Menurut Arikunto dalam Afrizal (2019:10) "sampel merupakan separuh dari populasi yang diteliti, sampel secara singkat diartikan sebagai bagian dari populasi yang menjadi sumber data yang sebenarnya, dalam suatu penelitian.Pengambilan sempel dilakukan secara purposive sampling yang merupakan teknik pengambilan sempel yang berdasarkan atas suatu pertimbangan tertentu seperti sifat-sifat populasi ataupun ciri-ciri sudah diketahui sebelumnya.Berdasarkan kriteria tersebut yang memenuhi menjadi sempel adalah kelompok junior dan senior dengan jumlah 8 atlet yang mengikuti latihan TC di Dojang Lebong. Instrument tes yang digunakan dalam penelitian ini adalah "Tes Tendangan Dollyo Chagi", sedangkan teknik analisis data statistik memakai uji normalitas liliefors yaitu untuk mengetahui apakah data berasal dari yang berdistribusi normal atau tidak dengan taraf signifikan $a=0,05$.

\section{HASIL DAN PEMBAHASAN}

\section{Hasil Penelitian}

Uji normalitas dilakukan dengan uji Lilliefors dengan taraf signifikan 0,05 dengan hasil dari pengujian persyaratan sebagai berikut: Uji normalitas dilakukan dengan uji Lilliefors, hasil uji normalitas terhadap variable penelitian yaitu hasil kemampuan Tendagan dollyo chagi (pretes dan postes).

Tabel 6. Hasil Uji Normalitas Data Pretes dan Post Tes

\begin{tabular}{|l|l|l|l|c|}
\hline \multicolumn{1}{|c|}{ Variabel } & Kelompok & \multicolumn{1}{|c|}{ L $_{\text {hitung }}$} & L tabel & Keterangan \\
\hline $\begin{array}{l}\text { Latihan kelentukan } \\
\text { terhadap tendangan } \\
\text { dollyo chagi }\end{array}$ & Pre tes & 0,2258 & 0,285 & Normal \\
\cline { 2 - 5 } & Pos tes & 0,2198 & & \\
\hline
\end{tabular}

Dari tabel diatas didapatkan Pre tes $\mathrm{L}_{\text {hitung }} 0,2258<\mathrm{L}_{\text {tabel }} 0,285$ dengan demikian dapat disimpulkan bahwa kelompok data pre test penelitian ini diambil dari populasi yang berdistribusi normal.Untuk pengujian data pos tes didapatkan hasil $\mathrm{L}_{\text {hitung }} 0,2198<\mathrm{L}_{\text {tabel }} 0,285$.

Pengujian Hipotesis Setelah melakukan persyaratan analisis diuji dan ternyata semua data variabel memenuhi persyaratan untuk melakukan pengujian hipotesis. Uji statistik yang digunakan adalah t-test dengan taraf signifikan 0,05. Terdapat pengaruh latihan kelentukan terhadap tendangan dollyo chagi dengan tes tendangan dollyo chagi dengan skor rata-rata 13,88 dan standar deviasi 1,46 pada pre test, dan setelah diberikan perlakuan sebanyak 16 kali skor ratarata 16,25 dan standar deviasi 1,04 pada post test.

Tabel 7. Hasil Pengujian Hipotesis

\begin{tabular}{|c|c|c|c|c|c|c|}
\hline $\begin{array}{c}\text { Latihan } \\
\text { Kelentukan }\end{array}$ & Mean & SD & $\mathrm{t}_{\text {hitung }}$ & $\mathrm{t}_{\text {tabel }}$ & Hasil Uji & Ket \\
\hline Pre test & 13,88 & 1,46 & \multirow{2}{*}{3,64} & 1,89 & $\begin{array}{c}\text { Signifik } \\
\text { an }\end{array}$ & $\begin{array}{c}\text { Ha } \\
\text { Diterima }\end{array}$ \\
\hline Post test & 16,25 & 1,04 & 3,6 & \\
\hline
\end{tabular}

Berdasarkan hasil uji statistik diperoleh nilai pre test dan post test latihan kelentukan terhadap tendangan dollyo chagi yang memiliki nilai $t_{\text {hitung }} 3,64$ dan nilai $t_{\text {tabel }} 1,89$, maka Ho ditolak dan Ha diterima, maka terdapat pengaruh antara latihan kelentukan dengan hasil tendangan dollyo chagi yang signifikan. Dilihat dari nilai rata-rata tendangan dollyo chagi, maka diperoleh nilai rata-rata pre test $=13,88$ dan nilai rata-rata pos test $=16,25$, karena nilai rata-rata post test lebih besar dari nilai rata-rata pre test maka terjadi peningkatan tendangan dollyo chagi sebesar $=$ 2,38 .

\section{Pembahasan}

Menutu Amdan (2019:37) Taekwondo merupakan olahraga beladiri yang maju yang beorientasi pada bela diri tradisional korea.Taekwondo yaitu seni beladiri yang menggunakan banyak teknik,tapi yang lebih banyak teknik tendangan (Cahyani,2015:23).Setiawan (2018:8) 
menyatakan taekwondo merupakan seni beladiri yang memakai teknik kaki dan tangan, dimana inti dari konsep taekwondo adalah gabungan dari kekuatan dan kemampuan. Kata "Taekwondo" diterjemahkan sebagai tae yaitu tendang dengan menggunakan kaki, kwon berarti memukul dengan kepalan tangan, dan do mengacu pada seni. Istilah ini secara langsung diterjemahkan ke dalam seni menendang dan meninju (Kazemi, 2010:23). Dalam olahraga taekwondo, tendangan merupakan senjata utama dalam melakukan serangan untuk memperoleh poin kemenangan. Salah satu tendangan yang sering digunakan pada saat pertandingan adalah tendangan dollyo chagi(Safitri,2019:17).Taekwondo memiliki ciri khas yaitu dengan penggunaan teknik menendang yang kuat.

Tendangan dollyo chagi yaitu bagian dari tendangan dasar di taekwondo dan tendangan yang paling mudah digunakan oleh atlet taekwondo dalam menyerang maupun bertahan atau membalas serangan lawan (Pribadita dan Sepriadi, 2019:46). Pratiwi (2017;6) berpendapat tendangan Dollyo Chagi atau bisa disebut jugatendangan sabit merupakan salah satu tendangan dasar yang dilatih pada tingkatan sabuk putih dan merupakan inti dari berbagai tendangan variasi tingkat lanjutan, karena bisa dikombinasikan dengan tendangan yang lain dan baiknya efektivitas tendangan dollyo chagi sehingga menjadi tendangan yang paling berguna. Suryadi dalam Triastuti (2016:5) Dollyo Chagi adalah tendangan melingkar depan, berat badan bertumpu pada pivot (titik tumpu putar) di ujung telapak kaki yangdigunakan untuk memutar, putar segera tubuh anda setelah menekuk lutut dan, ketika kaki dijulurkan, telapak kaki yang digunakan untuk menendang itu digerakan memutar secara horizontal sehingga bagiandepan telapak kaki (apchuck) itu dapat menendang sasaran atau bagian punggung kaki bisa digunakan untuk menendang (baldeng). Menurut Setiawan (2018:16) tendangan dollyo chagi adalah tendangan yang paling mudah digunakan untuk memperoleh point oleh para atlet taekwondo ketika bertanding. Kemudahan untuk melakukan gerakan, power yang dihasilkan besar, serta efektivitas dari tendangan merupakan alasan mengapa tendangan ini dipergunakan.

Kelentukan adalah kemampuan dari sendi-sendi tubuh untuk dapat melakukan gerakan secara maksimal sesuai dengan fungsi geraknya dalam melakukan suatu aktifitas tanpa terjadinya disfungsional atau cedera (Adnan, 2019:9).Kelentukan merupakan bagian yang penting pada setiap jenis olahraga prestasi.Kelentukan merupakan komponen kesegaran jasmani, sehingga kelentukan adalah kemampuan menggerakkan tubuh atau bagian bagiannya seluas mungkin tanpa terjadi ketegangan sendi dan cedera otot (Putra, 2020:2).Kelentukan adalah sebuah komponen motorik penting yang wajib dilatih dan ditingkatkan oleh atlet, terutama atlet muda (Wahyuni, 2020:3). Atlet taekwondo harus mampu melakukan tendangan yang tinggi kearah kepala lawan dikarenakan skor tertinggi ada dikepala, sehingga kelentukan sangat dibutuhkan untuk melakukan gerakan secara menyeluruh sehingga tidak terjadinya hambatan (Rizkiyanto, 2019:5). Pada Taekwondo kelentukan dibutuhkan dalam setiap gerakan agar gerakan menjadi sempurna.

Latihan bervariasi akan menciptakan suasana latihan yang menyenangkan bagi atlet sehingga dalam mengikuti latihan atlet tidak jenuh atau bosan dengan materi latihannya sehingga dapat mengikuti kegiatan dengan antusias (Rahmad, 2019:8). Dengan menggunakan variasi metode latihan kelentukan diharapkan atlet dapat meningkatkan tendangan dollyo chagi. Latihan yang teratur dengan progam latihan yang disusun dengan baik agar latihan menjadi maksimal (Yenes, 2018:3). Dengan latihan kelentukan atlet diharapkan mampu menguasai tendangan dollyo chagi dengan baik. Peningkatan ini terlihat saat pengambilan data post test tes tendangan dollyo chagi yaitu adanya penigkatan pada atlet yang mendapatkan latihan kelentukan.

\section{KESIMPULAN}

Berdasarkan analisis dan pembahasan yang telah dilakukan, maka dapat diperoleh kesimpulan sebagai berikut:Terdapat pengaruh latihan kelentukan terhadap tendangan dollyo chagi dengan $t_{\text {hitung }}=3,64>t_{\text {tabel }}=1,89$, sehingga didapankan nilai rata-rata pre test $=13,88$ dan nilai rata-rata post test $=16,25$, karena nilai rata-rata post test lebih besar dari nilai rata-rata pre test maka terjadi peningkatan tendangan dollyo chagi sebesar $=2,38$. Bagi atlet diharapkan melakukan latihan variasi yang lain, bagi peneliti berikutnya disarankan agar dapat melakukan penelitian tendangan dollyochagi dengan mengganti ataupun dengan menambahkan variabel-variabel latihan yang lain seperti kekuatan, Daya ledak dan juga memperluas lingkup penelitian. 


\section{DAFTAR PUSTAKA}

Amdan, A., \& Sepdanius, E. (2019). Tinjauan Ketepatan Tendangan Dollyo Chagi Atlet Taekwondo Di Smpn 2 Nan Sabaris. Jurnal Stamina, 2(4), 35-46.

Adnan, A. (2019). Contribution of L eg Muscle Explotion Power, Arm Muscle Explotion Power and Waist Flexibility Against Smash Ability. Performa Olahraga, 4(02), 83-91.

Afrizal, S. (2019). Hubungan antara Kelentukan dan Daya Ledak Otot Tungkai dengan Hasil Lompat Jauh. Jurnal Patriot, 2(2), 286-292.

CAHYANI, F. D. (2015). Pengaruh Latihan Beban Menggunakan Pemberat Kaki Terhadap Kemampuan Tendangan Dollyo Chagi Atlet Putra Taekwondo Kabupaten Dharmasraya. Jurnal Ilmu Keolahragaan, 1(1).

Dedi, K., \& Arwandi, J. (2020). Tinjauan Kondisi Fisik Atlet Renang Club Tirta Kaluang Padang. Jurnal Patriot, 3(1), 111-119.

Firdaus, G. Z. N., \& Sari, I. P. T. P. (2018). Pengaruh Latihan Dollyo Chagi Menggunakan Gawang Modifikasi Dan Pyongyo Terhadap Keterampilan Tendangan Dollyo Chagi Pada Peserta Ekstrakurikuler Taekwondo Sma Kolese De Britto Yogyakarta. Pendidikan Jasmani Kesehatan dan Rekreasi, 7(7).

Har, P. F., \& Sepriadi, S. (2019). Hubungan Daya Ledak Otot Tungkai dan Kelentukan terhadap Kemampuan Tendangan Dollyo Chagi Atlet Taekwondo kota Padang. Jurnal JPDO, 2(8), 4452.

Ihsan, N., Zulman, Z., \& Adriansyah, A. (2018). Hubungan Daya Ledak Otot Tungkai dan Dayatahan Aerobik Dengan KemampuanTendangan Depan Atlet Pencak Silat Perguruan Pedang Laut Pariaman. Jurnal Performa Olahraga, 3(1), 1-6.

Kazemi, M., Perri, G., \& Soave, D. (2010). A profile of 2008 Olympic Taekwondo competitors. The journal of the Canadian chiropractic association, 54(4), 243.

Lystad, R. P., Pollard, H., \& Graham, P. L. (2009). Epidemiology of injuries in competition taekwondo: A meta-analysis of observational studies. Journal of Science and Medicine in Sport, 12(6), 614-621.

Maizan, I. (2020). Profil Kondisi Fisik Atlet Bolavoli Padang Adios Club. Performa, 5(1), 17-25.

Putra, A. T., \& Afriza, S. (2020). Kontribusi Kelentukan dan Dayaledak Otot Tungkai terhadap Heading Sepakbola. Jurnal Patriot, 2(2), 616-626.

Pratiwi, G. P. (2017). Kelebihan Dan Kekurangan Kuda-Kuda Panjang Dan Pendek Pada Kecepatan Tendangan Dollyo Chagi Siswa Ekstrakurikuler Tae Kwon Do Smp N 2 Gamping. Pendidikan Jasmani Kesehatan dan Rekreasi, 6(10).

Rahmad, Ali, \& Syahara, S. (2019). Pengaruh Variasi Latihan Daya Ledak Otot Tungkai Terhadap Kecepatan Tendangan Depan Atlet Pencak Perguruan Anak Nagari Kabupaten Pesisir Selatan. Jurnal Patriot, 1(1), 123-130.

Rizkiyanto, P. P., Tirtawirya, D., \& Or, M. (2019). Profil Kondisi Fisik Atlet Taekwondo Kota Yogyakarta Dalam Menghadapi Porda Xv Diy Tahun 2019 Profile Of Physical Conditions At 
Taekwondo City Of Yogyakarta City In Facing Porda Xv Diy In 2019. Pend. Kepelatihan Olahraga- S1, 8(10).

Ridwan, M. (2020). Kondisi Fisik Pemain Sekolah Sepakbola (SSB) Kota Padang. Performa, 5(1), 92100.

Saputra, N., \& Aziz, I. (2020). Tinjauan Tingkat Kondisi Fisik Pemain Bolavoli Putra Sma 2 Pariaman. Performa, 5(1), 46-55.

Setiawan, Y., Amra, F., \& Lesmana, H. S. (2018). Analisis Tentang Cedera dalam Olahraga Beladiri Taekwondo di Dojang UNP. Jurnal Stamina, 1(1), 401-414.

Setiawan, Y., Sodikoen, I., \& Syahara, S. (2018). Kontribusi Kekuatan Otot Tungkai terhadap Kemampuan Dollyo Chagi Atlet Putera Tae Kwon Do di BTTC Kabupaten Rokan Hulu. Performa, 3(01), 15-15.

Soniawan,V., \& Irawan, R. (2018). Metode Bermain Berpengaruh Terhadap Kemampuan Ling Passing Sepakbola. Performa, 3(01), 42-42

Setiawan, Y., Sodikoen, I., \& Syahara, S. (2017). The Contribution of Leg Muscle Strength and Dynamic Balance Towards The Ability of Dollyo Chagi Kick.

Safitri, H. D. (2019). Pengaruh Latihan Beban Menggunakan ankle weight terhadap Kecepatan Tendangan Dollyo Chagi Atlit Taekwondo Putra Kabupaten Kerinci(Doctoral dissertation, Universitas Negeri Padang).

Triastuti, D., Ramadi, R., \& Juita, A.(2016) Hubungan Daya Ledak Otot Tungkai Dengan Tendangan Dollyo Chagi (Tendangan Melingkar) Atlet Taekwondo Paskhas Kota Pekanbaru(Doctoral dissertation, Riau University).

Wahyuni,S.(2020). Vo2max, Daya Ledak Otot Tungkai, Kelincahan dan Kelentukan untuk kebutuhan kondisi fisik atlet taekwondo.Jurnal Patriot, 2(2), 640-653.

Yenes, R., Syahara, S., \& Kiram, Y. (2018). Pengaruh Daya Ledak Otot Tungkai dan Keseimbangan terhadap Kemampuan Jump Shoot Atlet Bolabasket FIK UNP. 